\title{
Diurnal variation of various culture and biochemical parameters of Arthrospira platensis in large-scale outdoor raceway ponds
}

\author{
Nora Hidasi \& Amha Belay* \\ Earthrise Nutritionals LLC, Irvine, CA, 92612, USA
}

\begin{abstract}
The use of microalgae for nutraceuticals, food, and feed has recently gained great interest. Having a good understanding of the trends, including the diurnal variations, of the physiological parameters and biochemical composition of the biomass in commercial scale systems is of high importance as it may lead to finding potential ways to optimize productivity and product quality. Not much is known about the diurnal variation of the physiological parameters and biochemical composition of microalgae grown in large-scale outdoor raceway ponds in general and Arthrospira in particular, even though a lot is known about such diurnal variations in natural aquatic and laboratory environments. Arthrospira (Spirulina) platensis is a filamentous cyanobacterium widely used as dietary supplement, functional food, food, and animal feed. It has been grown commercially for about 40 years. In the present experiments the diurnal variation of some photosynthetic parameters and of the product quality was studied in Arthrospira platensis grown outdoors in a $5000 \mathrm{~m}^{2}$ raceway pond over a 24 hour period at three different months of the year. Specific trends for Arthrospira in commercial scale setup were described for the first time. Significant variation was observed in the biomass composition throughout the course of the day. The photosynthetic pigment content of Arthrospira (chlorophyll a, total carotenoids, and total phycocyanin) declined during the light hours, and recovered during the night. The same pattern was seen in the case of the crude protein content of the biomass. The total carbohydrate content however showed an opposite trend to that of the protein. Selected parameters were simulated in the lab in benchtop photobioreactors and the trends were compared with the large-scale system. The results of the experiments are discussed in relation to diurnal changes in some physical and chemical factors.
\end{abstract}

Keywords: Arthrospira (Spirulina) platensis, diurnal variation, raceway pond, photoinhibition, photosynthetic pigment, mass culture

* Corresponding author at: Earthrise Nutritionals LLC, 2151 Michelson Drive, Ste 258, Irvine, CA, 92612, USA Email address: abelay@earthrise.com 
Abbreviations: DIC - Dainippon Ink and Chemicals; Fo - minimal fluorescence yield; Fm - maximal fluorescence yield; Fv/Fm - maximum quantum yield of photosystem II; DO - dissolved oxygen; PAM - pulse amplitude modulated; PAR photosynthetically active radiation; PBR-photobioreactor; PC-phycocyanin; PSII-photosystem II; ROS - reactive oxygen species; SLL - simulation at low light

\section{INTRODUCTION}

Recently there has been an increased interest in the use of microalgae for food, nutraceuticals and feed. From an industrial point of view a comprehensive knowledge of the trends in the biochemical composition of the biomass in production scale systems is of high importance. Understanding the mechanisms that lie behind the diurnal variation of the physiological parameters and biochemical composition of the algae may shed light on potential ways of optimizing productivity and product quality.

There have been numerous studies published on the diurnal evolution of photosynthesis and photosynthetic pigment content (chlorophyll and carotenoids) of phytoplankton populations in natural water bodies, principally in marine and estuarine environments [1], [2], [3], [4], [5], [6], including primary production and diel oxygen rhythm [4], [7]. In some of the more recent works pulse amplitude modulated (PAM) fluorometry was used to get a deeper understanding of the photosynthetic processes [5], [6]. Defined patterns were observed over the course of 24 hours. Some authors proposed the diurnal change in light intensity [1], [2], [3], [5] temperature, and nutrient concentration [2] as possible reasons for the periodicity.

A number of laboratory studies published focus on the diel patterns of photosynthesis, photosynthetic pigment content (chlorophyll, phycocyanin, and carotenoids), growth, and cell division cycle, including the relationship of these parameters to each other, related to individual algae species rather than phytoplankton populations [8], [9], [10], [11], [12], [13], [14]. In these laboratory experiments the algae were normally exposed to different light and temperature trends (light-dark cycles with constant light intensity in the light phase using artificial illumination, constant temperature) than those prevailing outdoors. Therefore these studies did not take into account the potential effect of the typical diurnal fluctuation of light and temperature on the studied parameters. Nevertheless a laboratory setup makes it possible to evaluate whether only external resources control the diel variation of certain metabolic processes and cell components, or internal regulatory mechanisms (circadian clock) are as well involved. Circadian rhythms are endogenous biorhythms driven by a circadian clock. They possibly arose to give an evolutionary advantage to primitive organisms by either making it possible for certain physiological processes (i.e. DNA synthesis) to take place at night to avoid the potential damages caused by strong solar radiation reaching the early Earth, or by enabling to separate incompatible reactions in time (i.e. nitrogen fixation and photosynthesis). Circadian rhythms are 
characterized by: having a free-running period of approximately $24 \mathrm{~h}$ in the absence of external time cues, being entrainable (especially by light-dark and temperature cycles), and exhibiting temperature compensation. Cyanobacteria are the simplest organisms recognized to have circadian oscillators [15], [16]. The usual way to examine whether the diel pattern of certain process or cell component is controlled solely by exogenous factors or endogenous factors are as well involved in the regulation is to perform studies using light and dark cycles, then examine the variations of the parameter in question at continuous light [11], [12], [13]. If the rhythm persists at continuous light with a period of about $24 \mathrm{~h}$ it can be said that internal mechanisms are involved in its regulation [15], [16]. Ragni, M. \& D'Alcala, M. R. (2007) found that external resources such as the light availability, internal regulatory mechanisms, and the cell cycle all affect certain parameters, more specifically the synthesis of photosynthetic and photoprotective pigments studied in their experiment in a diatom species [11].

Diurnal studies of indigenous phytoplankton communities in natural water bodies, and diel experiments in laboratory conditions with select algae species may give an indication on what might happen in large-scale biomass cultures, nevertheless they possibly cannot fully describe the trends and the extent of the variation in the composition and physiological parameters of the cultivated alga. There are many interdependent biotic and abiotic factors (evolution of the light availability, temperature, nutrient availability, dissolved oxygen concentration, presence of other organisms etc.) influencing the behavior of the alga in commercial scale cultures that may be hardly reproducible in laboratory conditions, and the effect of which may be difficult to infer from studies of phytoplankton populations in their natural environment.

There were several experiments carried out with Spirulina platensis in small-scale raceway ponds (the work performed by Richmond, A. \& Vonshak, A. (1978) [17] being the first one) studying the diel evolution, especially during the light hours, of physiological processes such as photoinhibition, growth (estimated by oxygen production rate) and of parameters such as the temperature and dissolved oxygen concentration [17], [18], [19], [20], [21], [22], however the extent of these variations may not translate to large-scale systems. In commercial scale raceway ponds the mixing conditions might be different than in small scale systems, affecting the morphology, dissolved gas concentrations, light and nutrient availability to the algae, and therefore potentially the biomass composition. In large ponds there is usually insufficient turbulence attained by paddlewheel mixing, especially in Arthrospira platensis cultures where too vigorous mixing would prevent to maintain an optimal trichome shape and might lead to filament breakage [23]. The heat transfer is also different in small-scale and large-scale ponds.

The present studies were carried out with Arthrospira (Spirulina) platensis in a large $5000 \mathrm{~m}^{2}$ area experimental outdoor raceway pond. Arthrospira platensis is a multicellular filamentous planktonic cyanobacterium. It has a long history of human use, and has gained a lot of attention due to its potential health benefits including antioxidant/anti-inflammatory and immune 
regulation effects. It is widely used as dietary supplement, functional food, food, and animal feed, and has been grown commercially for about 40 years [24].

The importance and objective of the present diurnal studies lies in establishing a baseline for further growth and quality enhancement research in large-scale Spirulina cultivation, as no relevant study was found in the literature on the diel pattern of the culture parameters and biochemical composition of Arthrospira platensis in commercial scale biomass cultures. The experiments aimed to describe the diurnal trends at different months of the year.

Besides the large-scale experiments we also carried out a laboratory simulation, monitoring selected parameters, and compared the large-scale and the small-scale systems' behavior. Our intention was to highlight some parameters that may be important in designing simulation experiments in the future.

\section{MATERIALS AND METHODS}

\subsection{Diurnal studies in a large outdoor raceway pond}

The experiments were carried out at Earthrise Nutritionals LLC's Calipatria, CA location. The large-scale diurnal studies were performed in an experimental $5000 \mathrm{~m}^{2}$ area outdoor raceway pond. In the experimental pond the initial culture depth was approximately $21 \pm 1 \mathrm{~cm}$, and the estimated average culture flow velocity was $29 \mathrm{~cm} / \mathrm{s}$. The strain used was Arthrospira (Spirulina) platensis. Modified Zarrouk’s culture medium was used [25]. The initial $\mathrm{pH}$ was adjusted to $10.1 \pm 0.1$ prior to the experiments. $\mathrm{No} \mathrm{CO}_{2}$ was supplied for $\mathrm{pH}$ adjustment during the studies.

Three experiments were performed at three different months of the year: March (3/16/16 - 3/17/16), April (4/12/16 4/13/16), May (5/10/16 - 5/11/16). 10 samples were collected during each experiment from 5:00 am the starting day until 8:00 am the following day. The sampling took place every 3 hours. The samples were taken from the well-mixed zone after the paddlewheel, to ensure representative sampling. Two types of samples were collected at each sampling time: $500 \mathrm{ml}$ liquid sample for immediate analysis; 70 - 1201 filtered biomass sample to be analyzed later. Regarding the latter sample type: The filtration took place on site. A $1 \mathrm{~mm}$ opening size sieve was used as a first step to take out any possible debris or foreign material from the culture to be filtered. The biomass was then filtered using $20 \mu \mathrm{m}$ opening size sieves. After this, the biomass was further concentrated in the laboratory via a vacuum filtration apparatus, and was put in the freezer at $-20{ }^{\circ} \mathrm{C}$. The frozen biomass was freeze-dried by a Virtis Benchtop 6K ES freeze-dryer. Within 24 hours after having taken the samples off the freeze-dryer each dry sample was separated in small bags (one bag for each analysis to be performed), and the small bags were 
individually vacuum-sealed in DIC oxygen barrier bags (i.e. bags resistant to oxygen diffusion). The vacuum-sealed bags were opened right before the analysis. The purpose of this process was to maintain the integrity of the sample during the storage time, and minimize any biomass quality degradation by oxidation.

The following parameters were measured from the $500 \mathrm{ml}$ liquid samples: ash-free dry weight, optical density at $540 \mathrm{~nm}$, chlorophyll fluorescence and $\mathrm{pH}$. The measurements were done in triplicates except for the $\mathrm{pH}$.

The ash-free dry weight was measured by collecting a determined volume of culture on a pre-rinsed filter, drying it to a constant weight at $105^{\circ} \mathrm{C} \pm 5{ }^{\circ} \mathrm{C}$, and incinerating it in a muffle furnace for one hour at $550{ }^{\circ} \mathrm{C} \pm 10{ }^{\circ} \mathrm{C}$. The filter + dish weight was measured at each step (empty filter + dish, filter + dish after oven-drying, filter + dish after incineration), and the ash-free dry weight was calculated based on the measured weights according to the following simplified formula: $[\mathrm{mg} / \mathrm{l}]=\frac{A-B}{V} \times$ 1000 . Where $\mathrm{A}=$ filter + dish weight after oven-drying $[\mathrm{mg}], \mathrm{B}=$ filter + dish weight after incineration $[\mathrm{mg}], \mathrm{V}=$ sample volume filtered $[\mathrm{ml}]$.

The optical density was determined spectroscopically at $540 \mathrm{~nm}$, using deionized water as a blank.

The chlorophyll fluorescence was measured by pulse amplitude modulated (PAM) fluorometry using a Walz MINI-PAM photosynthesis yield analyzer. $10 \mathrm{ml}$ of sample was placed in the dark for 30 minutes right after sampling. After dark-adaptation the fiberoptics was placed in the sample and the Fo (minimal fluorescence yield) was determined. Then, after a saturation light pulse, the Fm (maximal fluorescence yield) was measured. The maximum quantum yield of photosystem II (Fv/Fm) was

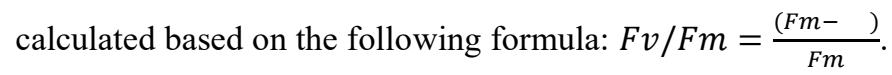

The $\mathrm{pH}$ was measured with an Orion Research digital $\mathrm{pH} /$ millivolt meter.

A Eureka Manta 2 multiprobe was placed in the experimental pond during the studies to monitor the water temperature, the temperature compensated conductivity, and dissolved oxygen. The logging interval was set to 10 minutes.

The photosynthetically active radiation (PAR) during the studies was measured using a LI-COR LI-1400 data logger and a LI-190 quantum sensor.

The following parameters were measured from the freeze-dried samples: chlorophyll a, total carotenoids, total phycocyanin, crude protein, ash, moisture. The measurements were done in triplicates for the chlorophyll, total phycocyanin, crude protein, and ash. They were performed in duplicates for the total carotenoids and moisture. The samples of the $3^{\text {rd }}$ experiment (May) were sent to an external lab for total fat analysis in order to calculate the carbohydrate content of the biomass.

The chlorophyll content of the biomass was determined by methanol extraction. The absorbance of the extract was measured spectroscopically at $665 \mathrm{~nm}$, correcting for turbidity at $750 \mathrm{~nm}$ for the calculation [26], [27]. 
The total carotenoid content of the biomass was extracted by using organic solvents (n-hexane, acetone, methanol, toluene, ether) and a saponification reaction, and was quantified spectroscopically using the absorbance measured at $453 \mathrm{~nm}$ for the calculation [28].

The total phycocyanin (c-phycocyanin and allophycocyanin) content of the biomass was determined spectrophotometrically according the Yoshikawa, N. \& Belay, A. (2008) [29].

The crude protein content of the samples was determined according to the Kjeldahl method by acid digestion, using 6.25 as a factor to estimate the \% protein from the $\mathrm{N}$ content of the biomass [28].

The ash content of the biomass was determined by incinerating the sample in a muffle furnace at $750{ }^{\circ} \mathrm{C} \pm 10{ }^{\circ} \mathrm{C}$. The empty crucible weight and the crucible weights with the sample before and after incineration were recorded. The ash content of the biomass was calculated based on the measured weights [28].

The moisture content of the biomass was measured by drying the sample at $110{ }^{\circ} \mathrm{C} \pm 2{ }^{\circ} \mathrm{C}$ to a constant weight. The empty dish weight and the dish weights with the sample before and after drying were recorded. The moisture content of the biomass was calculated based on the measured weights [28].

The fat content of the biomass was determined by an external lab by acid hydrolysis [28].

The total carbohydrate content of the biomass was determined by calculating the percentage remaining after all the other components have been measured $(\%$ carbohydrates $=100-\%$ moisture $-\%$ ash - $\%$ protein - $\%$ fats $)$.

\subsection{Laboratory simulation}

Three Phenometrics ePBR laboratory benchtop photobioreactors were used for the experiment. The ePBR were designed to simulate the environmental conditions prevailing in outdoor algal production ponds, with a special focus on light penetration. The main components of the ePBR are: a conical culture vessel (dimensions: height $=27 \mathrm{~cm}$, top diameter $=6.7 \mathrm{~cm}$, bottom diameter $=4.6 \mathrm{~cm}$ ) partially surrounded by a temperature control jacket that works based on the Peltier-effect, temperature probes monitoring the culture and the jacket temperature, white LED for illumination from the top, magnetic stirrer for the mixing, and the control software. The LED light spectrum has a major peak in the violet-blue region and a minor peak in the green-yellow region [30]. The inoculation volume of each reactor was $475 \mathrm{ml}$ to achieve a comparable initial depth to what was observed in the large open raceway pond. The same algae strain, Arthrospira platensis, was used for the study as for the experiments performed in the $5000 \mathrm{~m}^{2}$ area outdoor raceway pond. 
The May (5/10/16 - 5/11/16) experimental conditions (PAR and water temperature in the large pond) were chosen to be simulated in the lab. The light and the temperature conditions were approximated by the reactors via sinusoidal simulation. The maximum PAR value and the day length were set to $1879 \mu \mathrm{mol} / \mathrm{m}^{2}$ and $13.8 \mathrm{~h}$ respectively. The minimum and maximum water temperature were set to $19^{\circ} \mathrm{C}$ and $32^{\circ} \mathrm{C}$ respectively. The same conditions were set in all three reactors. The $\mathrm{pH}$, the nutrient medium, the starting conductivity, the starting biomass concentration, the culture column depth were comparable to the largescale study. The culture was adapted to the experimental conditions before the study. Just as during the large-scale study, no $\mathrm{CO}_{2}$ was added for $\mathrm{pH}$ control throughout the experiment. The mixing was achieved via a magnetic stirrer below the culture vessel set to $200 \mathrm{rpm}$, and a stir bar inside the culture vessel.

Samples were taken every 3 hours from the 3 reactors. The following parameters were measured for the liquid samples: optical density at $540 \mathrm{~nm}$, chlorophyll fluorescence, and \% dissolved oxygen, conductivity, and $\mathrm{pH}$.

The optical density and the chlorophyll fluorescence were determined in triplicates following the same method as described in the previous section for the experiments in the large outdoor raceway pond. The $\%$ dissolved oxygen and conductivity were measured by a YSI 550A dissolved oxygen instrument, and a YSI 5200A monitor and control instrument with a YSI 5562 probe assembly, respectively. The $\mathrm{pH}$ was measured with an Orion Research digital $\mathrm{pH} /$ millivolt meter.

\section{RESULTS AND DISCUSSION}

\subsection{Diurnal studies in a large outdoor raceway pond}

\subsubsection{Chlorophyll fluorescence as a measure of photoinhibition}

A marked midday depression was observed in the Fv/Fm values in all three experiments. The samples taken at $11 \mathrm{~h}$ and $14 \mathrm{~h}$, when the solar irradiance was the highest, showed significantly lower quantum yield values than the other samples (Figure 1.). The minimum $\mathrm{Fv} / \mathrm{Fm}$ values recorded were $0.452,0.423$, and 0.433 , the reduction compared to the morning maximum values being 13, 15, and 13\% respectively for the March, April, and May studies. The Fv/Fm recovered to the morning values by dusk in all three cases. The maximum PAR values were 1483,1845 , and $1879 \mu \mathrm{mol} / \mathrm{m}^{2} \mathrm{~s}$; the lengths of the day were 12 , 12.9 , and $13.8 \mathrm{~h}$; the morning ash-free dry weights on the first day of study (starting biomass concentration) were 820,480 , and $570 \mathrm{mg} / \mathrm{l}$ respectively for the March, April, and May experiments.

Using a chlorophyll fluorescence measurement methodology we can get information, in a fast and reliable way, on the quantum efficiency of photochemistry, to which the value of the maximum quantum yield of photosystem II (Fv/Fm) is directly 
related. Decline in the Fv/Fm value may show photoinhibition [18], [21] which is the inhibition of photosystem II activity under high light intensity [31]. It has long been known that photoinhibition exists in natural phytoplankton populations, Belay, A. (1981) being the first to demonstrate it experimentally in natural lakes [32]. Photoinhibition in outdoor small-scale Spirulina cultures (in $2.5 \mathrm{~m}^{2}$ area raceway ponds) was first described by Vonshak, A. \& Guy, R. (1988) [18], [19]. In the present largescale study the Fv/Fm values indicate significant photoinhibition of the culture during the midday hours, at the highest solar irradiances. In small scale raceway ponds different degrees of photoinhibition $(13,15$, and $25 \%$, depending on the algae strain) were found at midday at higher PAR levels (above $2000 \mu \mathrm{mol} / \mathrm{m}^{2} \mathrm{~s}$ ) for Spirulina platensis [19], [20], the values being in some cases comparable to our observations.

In all three months during the present large-scale study low water temperatures were measured, especially in the morning (Section 3.1.2., Figure 2.). Low water temperatures can aggravate the photoinhibitory effect [18], [33], [34], [35]. Photoinhibition is caused by the imbalance between the rate of photosystem II damage and repair [31]. The temperature dependence of photoinhibition might be explained by the PSII repair mechanism, as the repair process of some of the key components of the protein complex (i.e. D1 protein) is more temperature dependent than the destruction [33]. The effect of temperature on photoinhibition might also give an explanation to why the degree of photoinhibition was comparable in March, April, and May, even though the light conditions perceived by the culture were different in the three experiments due to different solar irradiances, lengths of day, and biomass concentrations. During the March experiment the biomass concentration was significantly higher and the peak solar irradiances were considerably lower than in the other two experiments, leading us to think that the photoinhibition should be less significant, nonetheless the lower water temperatures might have aggravated the inhibitory effect. In the present study, besides the low temperature effect, high dissolved oxygen concentrations in the pond during the day (Section 3.1.2., Figure 2.) could have additionally contributed to the photoinhibition of the algae [36], as also shown by other authors in outdoor Spirulina cultures [34].

Photoinhibition has various negative effects. It can reduce photosynthetic activity and growth [20], [21], [34], [35], [37]. It may also affect cellular pigment content as will be described in Section 3.1.3.

\subsubsection{Water temperature and \% dissolved oxygen}

During the present experiments water temperatures underwent significant variation throughout the day. The difference between the minimum temperature right after sunrise and the maximum temperature in the late afternoon was $12-13^{\circ} \mathrm{C}$. The

water temperatures throughout the experiments were suboptimal for A. platensis (below the optimal $35-38^{\circ} \mathrm{C}[23]$ ). The 
morning water temperatures were as low as $15^{\circ} \mathrm{C}$ (the minimum temperature for growth according to Belay (1997) [23]) during the March study, and 18 and $19^{\circ} \mathrm{C}$ during the April and May experiments respectively. The maximum temperatures were 26, 30 , and $32^{\circ} \mathrm{C}$ for the March, April, and May studies respectively (Figure 2.).

The changing water temperatures influence other parameters such as the nutrient solubility thus the nutrient availability, the dissolved gas concentration (i.e. the concentration of the dissolved oxygen), the metabolic rates and photosynthesis, hence the growth and the biomass composition [18], [38], [39]. As indicated in the previous section, the effect of the temperature on the photosynthesis may also show through the aggravation of photoinhibition.

In the present experiments the dissolved oxygen concentrations as well showed large variation throughout the course of 24 hours. The maximum dissolved oxygen concentrations reached approximately 450, 550, and 620\% saturation in the afternoon for the March, April, and May experiment respectively. These are equivalent to approximately 37, 42, and $45 \mathrm{mg} / \mathrm{l}$. During the night the dissolved oxygen levels declined, the minimum DO concentrations being 50, 10, and 10\% for the March, April, and May experiments respectively (Figure 2.).

Dissolved oxygen concentrations are constantly affected by diffusion and aeration (via the paddlewheel mixing), photosynthesis and community respiration [4] [22], [40]. In large open pond systems the culture is not axenic. Besides Arthrospira, bacteria and zooplankton are also present, which influence the biomass concentration and evolution of the dissolved oxygen levels (via respiration). Very high peak dissolved oxygen concentrations were observed during the day in the present studies as a result of the intense photosynthetic activity. The differences in the peak oxygen concentrations between the experiments are related to the differences in algal productivity, as the mixing conditions and the culture depth were comparable. We nevertheless have to mention that at such a high dissolved oxygen concentrations (above $500 \%$ saturation) the measurement accuracy is low. As turbulent flow is predominant only in some sections of the large raceway configuration [33], being mainly laminar in a significant area of the pond, the degassing due to the mixing of the dissolved oxygen produced during photosynthesis may be less significant than in small-scale systems. During the night the dissolved oxygen levels declined due to community respiration.

High dissolved oxygen concentrations during the day may have significant implications concerning growth and product quality: potential inhibition of photosynthesis and growth, loss of the pigments [18], [41], [42], as it will be further discussed in Section 3.1.3. 


\subsubsection{Biomass composition: photosynthetic pigments}

In the present studies in large open ponds we observed defined trends throughout the course of 24 hours in the photosynthetic pigments of $A$. platensis. We monitored the chlorophyll a, total carotenoid, and total phycocyanin (cphycocyanin and allophycocyanin) concentrations. The values measured were corrected for the ash content. We observed a declining trend in all the pigment concentrations in the late morning - afternoon, and a recovery trend at night (Fig. 3.,4.,5.). The extent of the variation is shown in Table 1. Table 1. shows the maximum value the first day in the morning, and the minimum value in the afternoon. The extent of variation was the greatest for all the pigments during the April study. This might be due to the lower biomass concentration during the April study than during the two other experiments, hence increasing the light penetration in the pond and its potential effect on the pigment content. The biggest variation between the minimum and the maximum values were measured in the total phycocyanin content during the April and May study.

It is possible that the variations in the photosynthetic pigment levels in the present experiments were a direct response to the changes in the environment surrounding the cells (i.e. dissolved oxygen, temperature, and light levels). As indicated in Section 3.1.1., the algae experienced high light intensities at midday causing photoinhibition. The dissolved oxygen levels were also very high during a significant portion of the day (Section 3.1.2.). These factors might have acted in a synergic way.

Carotenoids in photosynthetic organisms have different roles: a) they are structural elements of the photosynthetic apparatus. b) They help broadening the light spectrum utilizable for the algae. c) They have a protective function, shielding the light-harvesting pigments from excessive solar radiation and high amounts of reactive oxygen species (also detrimental to other components such as lipids, proteins, and nucleic acids) formed especially under photoinhibitory conditions [43], [44], [45].

Some authors observed on a diurnal scale an increase in the photoprotective carotenoid content of natural phytoplankton communities (mainly haptophytes and dinoflagellates) with exposure to increasing solar irradiances during the day [5]. In the case of Arthrospira cultures, grown under high light intensity in a small-scale not diurnal but longer term outdoor study, an increase in the carotenoid content of the biomass was seen over time (days) as the algae adapted to the solar irradiances [46]. Based on the above cited studies, that highlight the photoprotective role of the carotenoids, in the present diurnal-scale experiments it was expected to have increased carotenoid levels during the day, when the solar radiation was higher, than during the night. Nevertheless we observed the opposite trend. The discrepancies between the findings of Doblin, M. A. et al. (2011) [5] and our observations could be due to the differences in the photoprotective mechanisms of the algae studied: cyanobacteria, and more specifically Arthrospira, lack the xanthophyll cycle, on the other hand state transitions (involving decoupling of phycobilisomes) and photoactive orange carotenoid protein based processes have an important role in their 
photoprotection [5],[45]. Nonetheless the results of the study performed by Gao, K. \& Ma, Z. (2008) [46] with Arthrospira still suggest that in our experiments with increasing solar radiation there should be a rise in the carotenoid content during the day. It is possible that in our experiments (that were on a diurnal scale as opposed to the cited study) the level/generation rate of ROS in the midday hours was so high that part of the carotenoids got oxidized. (Even though there was possibly increased biosynthesis of carotenoids, the level of the oxidative damage to the carotenoids might have been more significant.) Furthermore, there are various references in the literature that report on pigment loss in phytoplankton, and more specifically in Spirulina, at high dissolved oxygen concentrations in the culture medium [41], [42], which was the case in the present study during a significant part of the day. A laboratory study with Spirulina platensis culture exposed to various dissolved oxygen concentrations (from 1 to $22.5 \mathrm{mg} / \mathrm{l}$ ) showed a decline in the pigment content (chlorophyll a, phycocyanin, and carotenoids) with the increase of dissolved oxygen levels and the time of exposure [41]. The negative effect of high oxygen concentrations on the pigments in Spirulina biomass was also demonstrated in small scale experiments by other authors [42]. Contrary to the above cited experiments (that lasted up to several days), in the present diurnal studies the culture was not exposed continuously to high oxygen levels. Lower oxygen levels during the night might have allowed the algae to recover from the damaging effect of high dissolved oxygen concentrations during the day. The evolution of the total carotenoids in a large open pond environment should be studied more closely to learn more about the biosynthetic rates, the rates of the oxidative damage, the light intensities at which photoprotecion is activated, and the processes involved.

No similar trend to what was observed in the present experiments was described by other authors regarding the total phycocyanin content. The only study found depicting the diurnal phycocyanin pattern in Arthrospira platensis shows a higher phycocyanin content during the day than during the night, the phycocyanin content being greater at the end of the light cycle than at the end of the dark cycle. Nevertheless the cited experiment was performed under controlled laboratory light and temperature conditions, with small-scale culture most likely not exposed to such high stress during the day as the algae in our study. Additionally the sampling frequency over a period of 24 hours was not as high as in our case [14]. In the present study strong light intensities around midday might be the reason for the decline in the total phycocyanin concentrations during a significant part of the daylight hours. Light intensity is an important environmental factor influencing the phycobilisomes (that function as peripheral light-harvesting organelles) in cyanobacteria [47], [48]. It was observed by some authors that Arthrospira platensis cells grown at high light intensities in the laboratory had lower phycobiliprotein content than low light grown cells. They noticed a substantial reduction in the phycocyanin content of the biomass after a rapid shift from low to high light intensity, and a significant pigment accumulation when changing form high to low light intensity [47]. In our experiments the 
decline in the total phycocyanin content of the cells during a great part of the light hours could also be due to oxidative stress exacerbated by the photoinhibitory conditions during the midday hours [43], and high dissolved oxygen levels during a significant portion of the day [41], [42]. The phycocyanin content of the cells could recover during the night at lower dissolved oxygen concentrations.

The cellular chlorophyll a trends obtained during the present studies appear to be in line with some of the patterns observed for natural algae communities [1], [2]. The diel variation of the cellular chlorophyll content might also be controlled by oxidative stress [41], [42], [43] and changing light conditions [47], [48], in the same way as described above for the total phycocyanin.

In order to evaluate whether besides the external factors internal regulatory mechanisms are also involved in the evolution of the chlorophyll a and the accessory pigments throughout the course of the day more in depth studies are necessary in constant conditions (in the absence of external time cues). Similar variations in constant conditions would indicate that the biological clock is involved in controlling these cellular components [15], [16]. The study of the diel variation of the photosynthetic pigments in relation to the cell cycle is also imperative.

\subsubsection{Biomass composition: protein and carbohydrates}

In the present experiments significant variation of the protein content of Arthrospira platensis was observed. The same trend was present as in the case of the photosynthetic pigments: There was a declining trend in the protein concentration during a significant part of the light hours. The protein concentration reached its lowest level in the late afternoon. Then, there was a recovery trend during the dark hours (Fig. 6.).

The total carbohydrate content of the samples collected during the May experiment was also measured and compared with the protein concentrations (Fig. 7.). We observed an opposite trend in the evolution of the $\%$ carbohydrates to the $\%$ protein throughout the course of 24 hours: The carbohydrate content of the biomass increased during the light hours, reaching its maximum in the late afternoon, and decreased during the dark hours.

The extent of variation in the \% protein and in the \% carbohydrates can be seen in Table 2 . The values measured were corrected for the ash content. Table 2. shows the maximum value the first day in the morning, and the minimum value in the afternoon.

There are various studies in the literature in which similar trends in the protein and carbohydrate content of phytoplankton were observed to what was found in the present experiments. In microalgae in general carbon storage reserves such as lipids 
or carbohydrates increase during the course of the day and decline at night [49]. The reserves built up throughout the day could be used for net protein synthesis at night [49], [50], or for other processes such as respiration [51]. In the case of Spirulina platensis cultures it was observed that under stress conditions, more specifically when the algae are grown at suboptimal temperatures or at high light intensities, as in the present experiments, there is a decline in the protein and an increase in the carbohydrate synthesis throughout the day, leading to a net increase in the carbohydrate concentration. The surplus of carbohydrates is then consumed during the night [51]. We also have to take into consideration the potential effect of the high dissolved oxygen concentrations during the day on the protein content of Arthrospira. Inhibition of protein synthesis in Spirulina cultures exposed to high levels of oxygen was observed by other authors, the inhibitory effect being temperature dependent (being more pronounced at lower than at higher, near optimal temperatures) [42]. Part of the variation in the protein content of the biomass may be due to the variation in the \% total phycocyanin (Section 3.1.3.).

Apart from the abovementioned external factors the circadian clock and the cell cycle may also play a role in the evolution of the cellular protein and carbohydrate content. Further studies are necessary to have a deeper understanding of their function in the control of these cellular components.

\subsection{Laboratory simulation}

The aim of the laboratory study was to evaluate how closely we can reproduce in benchtop photobioreactors the diurnal Fv/Fm and dissolved oxygen trends observed in the large-scale outdoor raceway pond. Light and dissolved oxygen concentration are potentially the two major stress factors affecting biomass composition and growth in the midday hours, therefore their close emulation is crucial when performing laboratory simulations.

As shown in Figure 8. the Fv/Fm values in the photobioreactors were in general lower than in the large raceway pond, which may indicate that the inoculum had not yet been fully adapted to the experimental conditions by the start of the study. The source of the inoculum was a winter outdoor culture. The winter culture conditions are significantly different from the May experiment simulation conditions. Even though the inoculum was grown in the lab at the simulation culture conditions for about a week prior to the start of the study, longer adaptation times appear to be necessary for a full acclimation. The Fv/Fm trend in the photobioreactors shows an increase from $5 \mathrm{am}$ to $8 \mathrm{am}$, a slight decline around the midday hours, a recovery at the end of the light hours, and a decline during the night. Looking at the light hours, the minimum value of the Fv/Fm close to midday was about $90 \%$ of the morning maximum value. The decreasing trend of the Fv/Fm during the night hours needs further investigation. 
Figure 9. shows the $\mathrm{Fv} / \mathrm{Fm}$ trend in a similar laboratory simulation ( $\mathrm{SLL}=$ simulation at low light) in the photobioreactors with the difference that for the sinusoidal simulation of the PAR the maximum value was set to $1400 \mu \mathrm{mol} / \mathrm{m}^{2} \mathrm{~s}$ (the day length remaining 13.8h), and the inoculum was from a late spring-summer outdoor culture that was fully adapted to the experimental conditions. The acclimation of the lab culture is shown by the fact that the $\mathrm{Fv} / \mathrm{Fm}$ values were in the same range as what was measured during the large-scale May experiment. The pattern was comparable to the previously described lab simulation. As described in Section 3.1.1., in the large outdoor pond there was a distinct depression of the Fv/Fm during the midday hours. The minimum value of the Fv/Fm was about $87 \%$ of the morning maximum value. A small decline at the highest PAR values was also observed in the SLL laboratory study, the minimum Fv/Fm value being approximately $95 \%$ of the maximum morning value. Even though the PAR values during this lab experiment were lower than in the outdoor study we may consider SLL more representative for the photobioreactor - outdoor large-scale study comparison regarding the $\mathrm{Fv} / \mathrm{Fm}$, as the culture was fully adapted to the experimental conditions.

There is an indication that photoinhibition in the midday hours is less significant in the photobioreactors than in the large outdoor pond. The reason for this might be the light spectrum used in the simulation compared to the solar radiation outdoors. Even though the spectral composition of the laboratory light source (having a major peak in the violet-blue region and a minor peak in the green-yellow region [30]) more or less fits the photoinhibition peaks in the PAR region described by Tyystjärvi, T. et al. (2002) [52], the lack of UV light might be the cause of the different response of the culture, resulting in reduced photoinhibition of the algae at midday indoors. The significance of UV radiation in the photoinhibition of phytoplankton [32], [52], including Arthrospira platensis [46], was demonstrated by several authors. Another reason for the different behavior might be the mixing. The mixing pattern created by paddlewheel mixing in large open ponds appears to be different from what was achieved in the lab scale setup by a magnetic stirrer. In large A. platensis raceway ponds the cells don't spend the optimal amount of time in the photic zone as the mixing is not vigorous enough. The flow in a large part of the pond is predominantly laminar, while turbulent flow prevails only in certain areas such as behind the paddlewheel and at the raceway bends. Consequently in the surface layers the cells experience high light intensities, nonetheless most of the cells reside in the darkness, as the photic zone is just a few centimeters deep. There is only a thin layer between these two where the light intensity is adequate for uninhibited photosynthesis [23], [33]. Inferring from studies performed in natural lakes [32] we might say that in the previously described raceway pond setup the overall photoinhibition of the algae is greater than in a completely mixed system (such as in the laboratory setup). In a raceway pond the photoinhibition is exacerbated by the fact that the algae on the 
surface are exposed to inhibitory irradiances for longer time, while the cells residing in the dark area, when exposed to strong light, have a higher sensitivity for photoinhibition.

The evolution of $\%$ dissolved oxygen concentration throughout the course of the day in the photobioreactors was also different from what was observed outdoors (Figure 10.). The maximum \% DO measured in the PBRs was $370 \%$ saturation versus the $620 \%$ observed for the large system. As the growth during the light hours was comparable in the large raceway pond and in the laboratory study (Figure 11.), the differences in the $\%$ DO concentrations are most likely due to the different mixing pattern in the two types of systems. In the PBRs more efficient mixing might have facilitated the degassing of the dissolved oxygen. The night increase of the optical density in the large raceway pond might be due to heterotrophic growth and/or vertical migration of non-photosynthetic organisms due to the change in dissolved oxygen concentrations. Other studies focusing on the simulation of small outdoor raceway pond cultures using Phenometrics PBRs found as well a divergence between the two systems' behavior. The overall growth (during the course of several weeks) in bioreactors was slower than in the open ponds [53].

The findings described in this section could be helpful in designing experiments aiming to simulate in small-scale laboratory systems what may happen in large outdoor raceway ponds, such as the studies performed by Huesemann, M. et al. (2017) [53], [54]. As indicated previously, the dissolved oxygen concentration of the medium can affect the biomass composition and the growth. Besides the light intensity the light spectrum also has a significant effect on the culture. These and other factors have to be looked at closely before performing simulations. 


\section{CONCLUSION}

The diurnal pattern of some culture and product quality parameters of Arthrospira platensis was studied in a large outdoor raceway pond at three different months of the year. Specific trends for Arthrospira in commercial scale setup were described for the first time. Significant variation was observed in the biomass composition throughout the course of the day. The photosynthetic pigment content of A. platensis (chlorophyll a, total carotenoids, and total phycocyanin) declined during the light hours and recovered during the night. The same pattern was seen in the case of the crude protein content of the biomass. The total carbohydrate content of Arthrospira however showed an opposite trend to that of the protein: The total carbohydrate content increased during the day and declined throughout the night. It is possible that the highly stressful environment during a significant part of the light hours: high light intensities inducing photoinhibition, substantial dissolved oxygen concentrations, suboptimal water temperatures, are the reason for the abovementioned diel trends in the biomass composition, the indicated factors acting most likely in a synergic way. Therefore when designing small-scale experiments in the laboratory aiming to modify the biomass composition (or to improve the growth) with the intention to scale up the results to large-scale raceway ponds, these factors have to be taken in consideration. The trends obtained in the present experiments provide valuable information for potential growth and biomass quality optimization in large-scale pond cultures. More in-depth studies are necessary to identify the exact physiological processes lying behind the compositional changes of Arthrospira platensis throughout the course of the day in a large-scale outdoor raceway pond. Further elucidation of the biochemical variations in relation to the cell cycle and circadian rhythm would be of great importance.

\section{ACKNOWLEDGEMENTS}

We thank Earthrise Nutritionals LLC for making this work possible, and Felipe Vega for his valuable contribution during sample collection and analysis. We also thank Dr. Luis M. Lubian Chaichio for his insightful comments. Moreover, we thank the anonymous reviewers for their valuable suggestions.

\section{DECLARATION OF AUTHOR CONTRIBUTIONS}

$\mathrm{AB}$ initiated the project; $\mathrm{AB}$ and $\mathrm{NH}$ planned the project, and designed the experiments; $\mathrm{NH}$ collected and analyzed the data under AB's scientific guidance. NH drafted the manuscript; AB performed critical revision of the manuscript. All authors read and approved the final manuscript, and take responsibility for the integrity of the work as a whole, from inception to finished article. 


\section{REFERENCES}

[1] Yentsch, C. S. \& Ryther, J. H. (1957) Short-Term Variations in Phytoplankton Chlorophyll and Their Significance, Limnology and Oceanography, 2 (2), 140-142

[2] Yentsch, C. S. \& Scagel, R. F. (1958) Diurnal study of phytoplankton pigments, an in situ study in East Sound, Washington, Journal of Marine Research, 17, 567-583

[3] Lorenzen, C. J. (1963) Diurnal variation in photosynthetic activity of natural phytoplankton populations, Limnology and Oceanography, $8(1), 56-62$

[4] Gieskes, W. W. C. \& Kraay, G. W. (1982) Effect of Enclosure in Large Plastic Bags on Diurnal Change in Oxygen Concentration in Tropical Ocean Water, Marine Biology 70 (1), 99-104

[5] Doblin, M. A., Petrou, K. L., Shelly, K., Westwood, K., van den Enden, R., Wright, S., Griffiths, B., Ralph, P. J. (2011) Diel variation of chlorophyll-a fluorescence, phytoplankton pigments and productivity in the Sub-Antarctic and Polar Front Zones south of Tasmania, Australia, Deep-Sea Research Part II 58 (21- 22), 2189-2199

[6] McMinn, A., Ryan, K., Gademann, R. (2003) Diurnal changes in photosynthesis of Antarctic fast ice algal communities determined by pulse amplitude modulation fluorometry, Marine Biology, 143 (2), 359-367

[7] Tijssen, S. B. (1979) Diurnal oxygen rhythm and primary production in the mixed layer of the Atlantic Ocean at $20^{\circ} \mathrm{N}$, Netherlands Journal of Sea Research, 13 (1), 79-84

[8] Mas, S., Roy, S., Blouin, F. (2008) Diel variations in optical properties of Imantonia rotunda (Haptophyceae) and Thalassiosira pseudonana (Bacillariophyceae) exposed to different irradiance levels, Journal of Phycology, 44 (3), $551-563$

[9] Jacquet, S., Partensky, F., Lennon, J. F., Vaulot, D. (2001) Diel patterns of growth and division in marine picoplankton in culture, Journal of Phycology, 37 (3), 357-369

[10] Hennige, S. J., Coyne, K. J., MacIntyre, H., Liefer, J., Warner, M. E. (2013) The photobiology of Heterosigma akashiwo. Photoacclimation, diurnal periodicity, and its ability to rapidly exploit exposure to high light, Journal of Phycology, 49 (2), 349-360 
[11] Ragni, M. \& D'Alcala, M. R. (2007) Circadian variability in the photobiology of Phaeodactylum tricornutum: pigment content, Journal of Plankton Research, 29 (2), 141-156

[12] Sorek, M., Yacobi, Y. Z., Roopin, M., Berman-Frank, I., Levy, O. (2013) Photosynthetic circadian rhythmicity patterns of Symbiodium, the coral endosymbiotic algae, Proceedings of the Royal Society B, 280 (1759), 20122942

[13] Prézelin, B. B., Meeson, B. W., Sweeney, B. M. (1977) Characterization of Photosynthetic Rhythms in Marine Dinoflagellates, Plant Physiology, 60 (3), 384-387

[14] Matallana-Surget, S., Derock, J., Leroy, B., Badri, H., Deschoenmaeker, F., Wattiez, R. (2014) Proteome-Wide Analysis and Diel Proteomic Profiling of the Cyanobacterium Arthrospira platensis PCC 8005, PLOS ONE, 9 (6), e99076

[15] Iwasaki, H. \& Kondo, T. (2000) The Current State and Problems of Circadian Clock Studies in Cyanobacteria, Plant \& Cell Physiology, 41 (9), 1013-1020

[16] Edery, I. (2000) Circadian rhythms in a nutshell, Physiological Genomics, 3 (2), 59-74

[17] Richmond, A. \& Vonshak, A. (1978) Spirulina culture in Israel, Archiv für Hydrobiologie, 11, 274-280

[18] Vonshak, A. (1997) Outdoor Mass Production of Spirulina: The Basic Concept, in Vonshak, A. (Ed.) Spirulina platensis (Arthrospira): Physiology, cell-biology and biotechnology, London, UK: Taylor \& Francis Ltd., 79-99

[19] Vonshak, A. \& Guy, R. (1988) Photoinhibition as a limiting factor in outdoor cultivation of Spirulina platensis, in Stadler, T., Mollion, J., Verdus, M.-C., Karamanos, Y., Morvan, H. \& Christiaen, D. (Eds) Algal Biotechnology, London: Elsevier Applied Sicence, 365-370

[20] Lu, C. \& Vonshak, A. (1999) Photoinhibition in outdoor Spirulina platensis cultures assessed by polyphasic chlorophyll fluorescence transients, Journal of Applied Phycology 11 (4), 355-359

[21] Vonshak, A, Laorawat, S., Bunnag, B, Tanticharoen, M. (2014) The effect of light availability on the photosynthetic activity and productivity of outdoor cultures of Arthrospira platensis (Spirulina), Journal of Applied Phycology, 26 (3), 13091315

[22] Guterman, H., Vonshak, A., Ben-Yaakov, S. (1989) Automatic on-line growth estimation method for outdoor algal biomass production, Biotechnology and Bioengineering, 132 (2), 143-152 
[23] Belay, A. (1997) Mass Culture of Spirulina Outdoors - The Earthrise Farms Experience, in Vonshak, A. (Ed.) Spirulina platensis (Arthrospira): Physiology, cell-biology and biotechnology, London: Taylor \& Francis Ltd., 131-158

[24] Belay, A. (2013) Biology and Industrial Production of Arthrospira (Spirulina), in Richmond, A. \& Hu, Q. (Eds) Handbook of Microalgal Culture: Applied Phycology and Biotechnology, Second Ed., Oxford, UK: John Wiley \& Sons Ltd., 339-358

[25] Zarrouk, C. (1966) Contribution à l'étude d'une cyanophycée: influence de divers facteurs physiques et chimiques sur la croissance et la photosynthèse de Spirulina maxima (Setchell et Gardner) Geitler, Ph.D. Thesis, Paris: University of Paris

[26] Vonshak, A. (1997) Appendices, in Vonshak, A. (Ed.) Spirulina platensis (Arthrospira): Physiology, cell-biology and biotechnology, London, UK: Taylor \& Francis Ltd., 213-226

[27] Talling, J.F. \& Driver, D. (1963) Some problems in the estimation of chlorophyll a in phytoplankton, in Proceedings, Conference on primary productivity measurement, marine, and freshwater, 1961, Hawaii, USA: University of Hawaii, US Atomic Energy Commission, Division of Technical Information, TID-7633, 142-146

[28] Official Methods of Analysis (2005), 18th Ed., AOAC INTERNATIONAL, Gaithersburg, MD, USA

[29] Yoshikawa, N. \& Belay, A. (2008) Single-Laboratory Validation of a Method for the Determination of c-Phycocyanin and Allophycocyanin in Spirulina (Arthrospira) Supplements and Raw Materials by Spectrophotometry, Journal of AOAC International, 91 (3), 524-529

[30] Lucker, B. F., Hall, C. C., Zegarac, R., Kramer, D. M. (2014) The environmental photobioreactor (ePBR): An algal culturing platform for simulating dynamic natural environments, Algal Research, 6, Part B, 242-249

[31] Nishiyama, Y., Allakhverdiev, S. I., Murata, N. (2006) A new paradigm for the action of reactive oxygen species in the photoinhibition of photosystem II, Biochimica et Biophysica Acta, 1757 (7), 742-749

[32] Belay, A. (1981) An experimental investigation of inhibition of phytoplankton photosynthesis at lake surfaces, New Phytologist, 89 (1), 61-74

[33] Jensen, S. \& Knutsen, G. (1993) Influence of light and temperature on photoinhibition of photosynthesis in Spirulina platensis, Journal of Applied Phycology, 5 (5), 495-504 
[34] Torzillo, G., Bernardini, P., Masojídek, J. (1998) On-line monitoring of chlorophyll fluorescence to assess the extent of photoinhibition of photosynthesis induced by high oxygen concentration and low temperature and its effect on the productivity of outdoor cultures of Spirulina platensis (Cyanobacteria), Journal of Phycology, 34 (3), 504-510

[35] Vonshak, A., Torzillo, G., Masojídek, J., Boussiba, S. (2001) Sub-optimal morning temperature induces photoinhibition in dense outdoor cultures of the alga Monodus subterraneus (Eustigmatophyta), Plant, Cell and Environment, 24 (10), 11131118

[36] Belay, A. \& Fogg, G. E. (1978) Photoinhibition of photosynthesis in Asterionella formosa (Bacillariophyceae), Journal of Phycology, 14 (3), 341-347

[37] Takahashi, S. \& Badger, M. R. (2011) Photoprotection in plants: a new light on photosystem II damage, Trends in Plant Science, $16(1), 53-60$

[38] Vonshak, A. (1997) Spirulina: Growth, Physiology and Biochemistry, in Vonshak, A. (Ed.) Spirulina platensis (Arthrospira): Physiology, cell-biology and biotechnology, London: Taylor \& Francis Ltd., 43-65

[39] Hu, Q. (2004) Environmental Effects on Cell Composition, in Richmond, A. (Ed.) Handbook of Microalgal Culture: Biotechnology and Applied Phycology, Oxford, UK: Blackwell Science Ltd., 83-93

[40] Ben-Yaakov, S., Guterman, H., Vonshak, A., Richmond, A. (1985) An automatic method for on-line estimation of the photosynthetic rate in open algal ponds, Biotechnology and Bioengineering, 27 (8), 1136-1145

[41] Marquez, F. J., Sasaki, K., Nishio, N., Nagai, S. (1995) Inhibitory effect of oxygen accumulation on the growth of Spirulina platensis, Biotechnology Letters, 17 (2), 225-228

[42] Torzillo, G., Giovannetti, L., Bocci, F., Materassi, R. (1984) Effect of Oxygen Concentration on the Protein Content of Spirulina Biomass, Biotechnology and Bioengineering, 26 (9), 1134-1135

[43] Carvalho, A. M. (2004) Circadian Protection against Oxidative Stress in Marine Algae, Hypnos, 1 (1), $142-157$

[44] Masojídek, J., Koblizek, M., Torzillo, G. (2004) Photosynthesis in Microalgae, in Richmond, A. (Ed.) Handbook of Microalgal Culture: Biotechnology and Applied Phycology, Oxford, UK: Blackwell Science Ltd., 20-39 
[45] Zakar, T., Laczko-Dobos, H., Toth, T. N., Gombos, Z. (2016) Carotenoids Assist in Cyanobacterial Photosystem II Assembly and Function, Frontiers in Plant Science, 7, 295

[46] Gao, K. \& Ma, Z. (2008) Photosynthesis and growth of Arthrospira (Spirulina) platensis (Cyanophyta) in response to solar UV radiation, with special reference to its minor variant, Environmental and Experimental Botany, 63 (1-3), 123-129

[47] Nomsawai, P., Tandeau de Marsac, N., Thomas, J. C., Tanticharoen, M., Cheevadhanarak, S. (1999) Light Regulation of Phycobilisome Structure and Gene Expression in Spirulina platensis C1 (Arthrospira sp. PCC 9438), Plant \& Cell Physiology, 40 (12), 1194-1202

[48] Lemasson, C., Tandeau de Marsac N., Cohen-Bazire, G. (1973) Role of Allophycocyanin as a Light-Harvesting Pigment in Cyanobacteria, Proceedings of the National Academy of Sciences of the United States of America, 70 (11), 31303133

[49] de Winter, L., Klok, A. J., Franco, M. C., Barbosa, M. J., Wijffels, R. H. (2013) The synchronized cell cycle of Neochloris oleoabundans and its influence on biomass composition under constant light conditions, Algal Research, 2 (4), $313-320$

[50] Cuhel, R. L., Ortner, P. B., Lean, D. R. S. (1984) Night synthesis of protein by algae, Limnology and Oceanography, $29(4), 731-744$

[51] Torzillo, G., Sacchi, A., Materassi, R. (1991) Temperature as an Important Factor Affecting Productivity and Night Biomass Loss in Spirulina platensis Grown Outdoors in Tubular Photobioreactors, Bioresource Technology, 38 (2-3), 95-100

[52] Tyystjärvi, T., Tuominen, I., Herranen, M., Aro, E. M., Tyystjärvi, E. (2002) Action spectrum of psbA gene transcription is similar to that of photoinhibition in Synechocystis sp. PCC 6803, FEBS Letters 516 (1-3), 167-171

[53] Huesemann, M., Dale, T., Chavis, A., Crowe, B., Twary, S., Barry, A., Valentine, D., Yoshida, R., Wigmosta, M., Cullinan, V. (2017) Simulation of outdoor pond cultures using indoor LED-lighted and temperature-controlled raceway ponds and Phenometrics photobioreactors, Algal Research, 21, 178-190

[54] Huesemann, M., Williams, P., Edmundson, S., Chen, P., Kruk, R., Cullinan, V., Crowe, B., Lundquist, T. (2017) Laboratory Environmental Algae Pond Simulator (LEAPS) Photobioreactors: Validation Using Outdoor Pond Cultures of Chlorella sorokiniana and Nannochloropsis salina, Algal Research, Accepted 


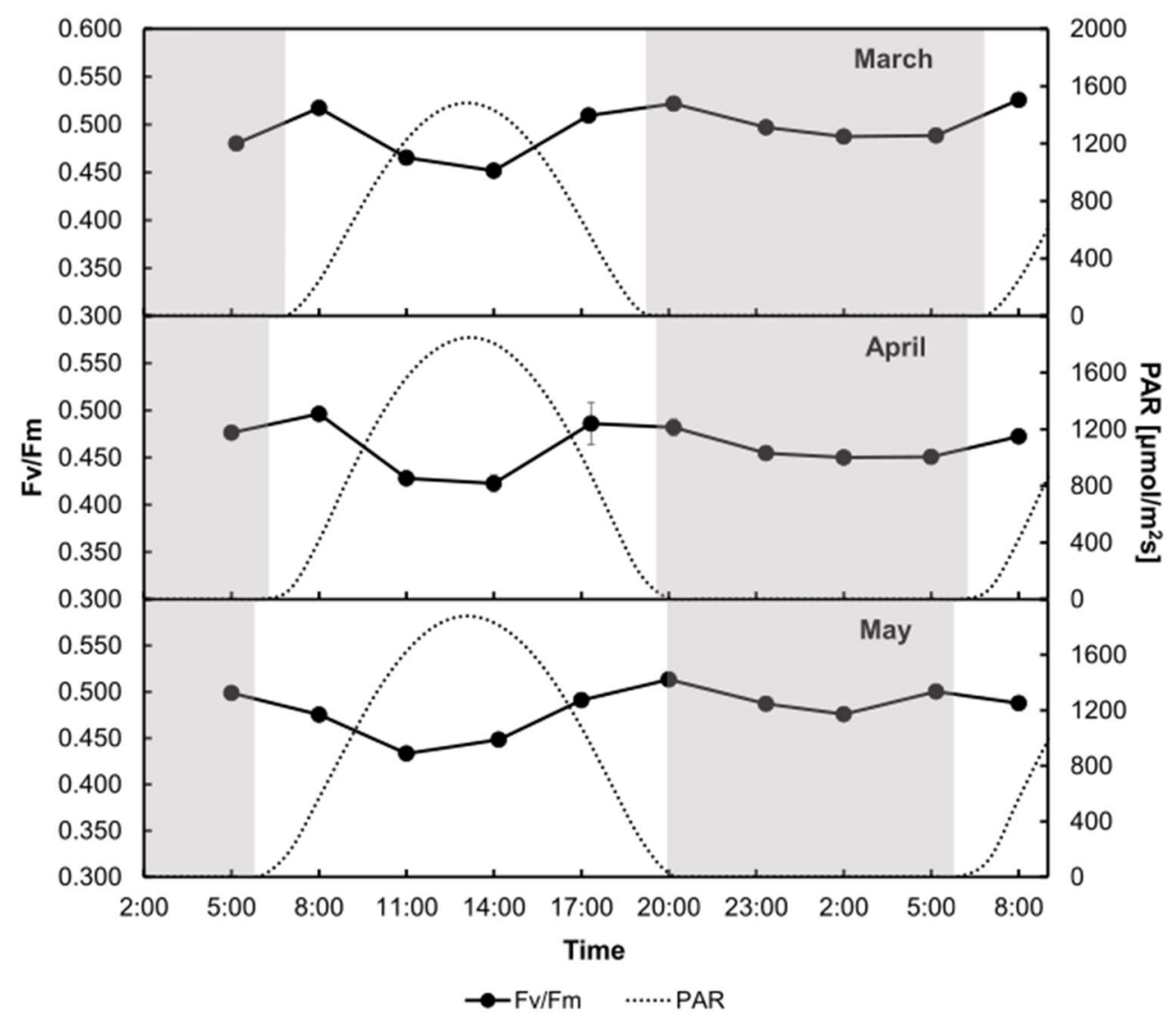

Fig. 1. Fv/Fm and PAR as a function of time throughout the March, April, and May experiments in a large-scale raceway pond; mean \pm standard deviation

\# Single-column fitting image \# 


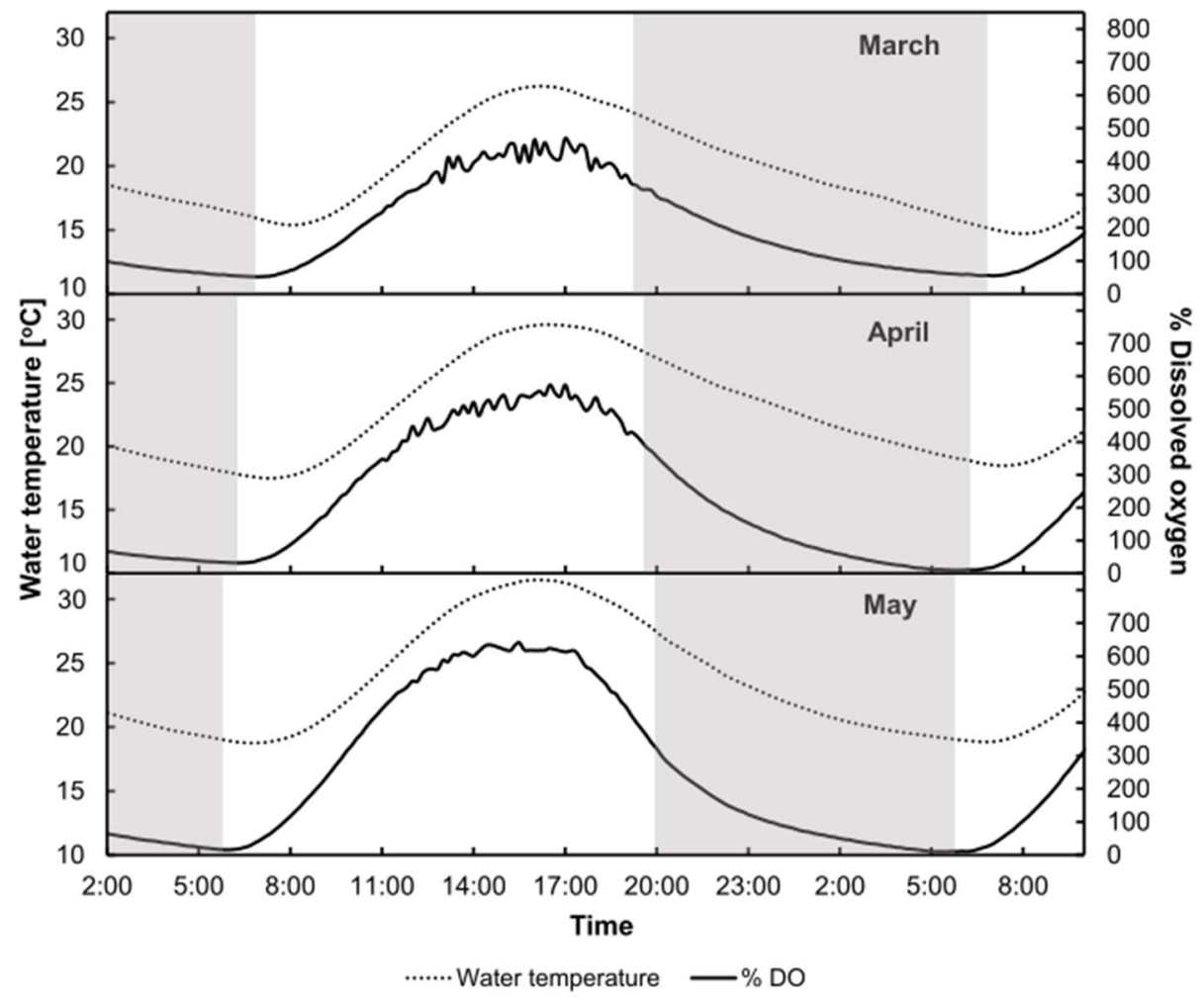

Fig. 2. Water temperature and \% dissolved oxygen as a function of time throughout the March, April, and May experiments in a large-scale raceway pond

\# Single-column fitting image \# 


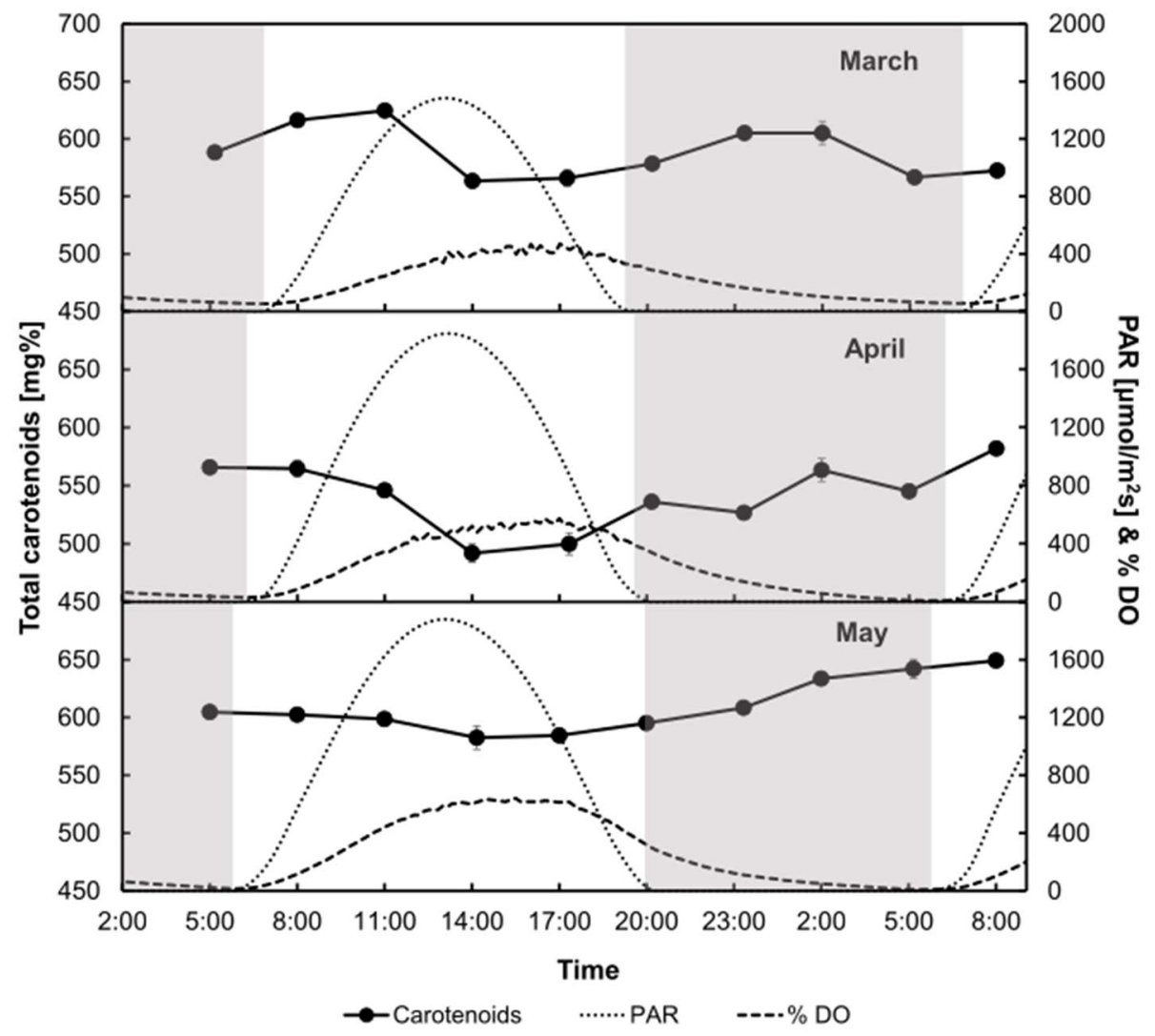

Fig. 3. $m g \%$ total carotenoids, PAR, and \% dissolved oxygen as a function of time throughout the March, April, and May experiments in a large-scale raceway pond; mean \pm standard deviation

\# Single-column fitting image \# 


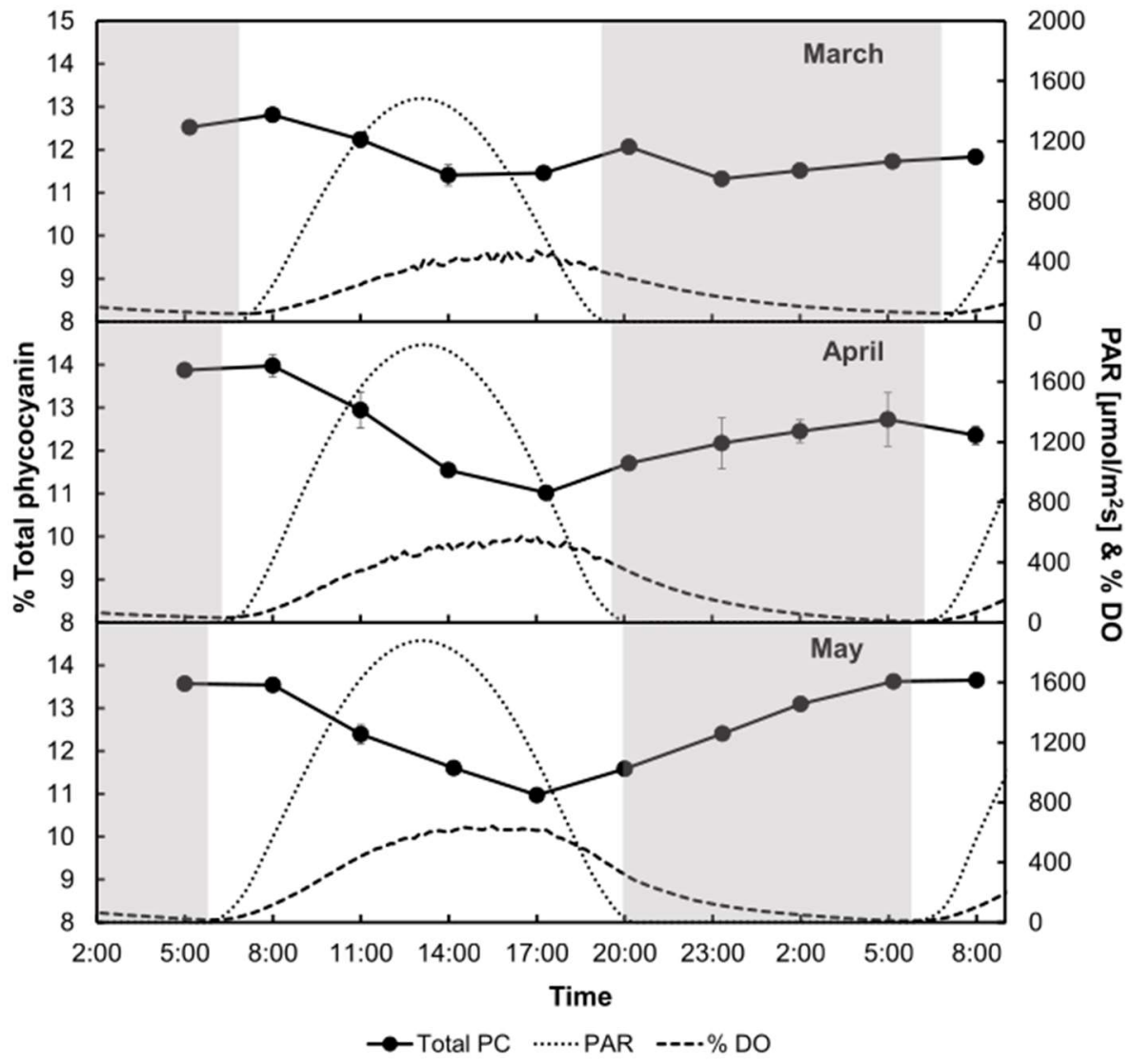

Fig. 4. \% total phycocyanin, PAR, and \% dissolved oxygen as a function of time throughout the March, April, and May experiments in a large-scale raceway pond; mean \pm standard deviation

\# Single-column fitting image \# 


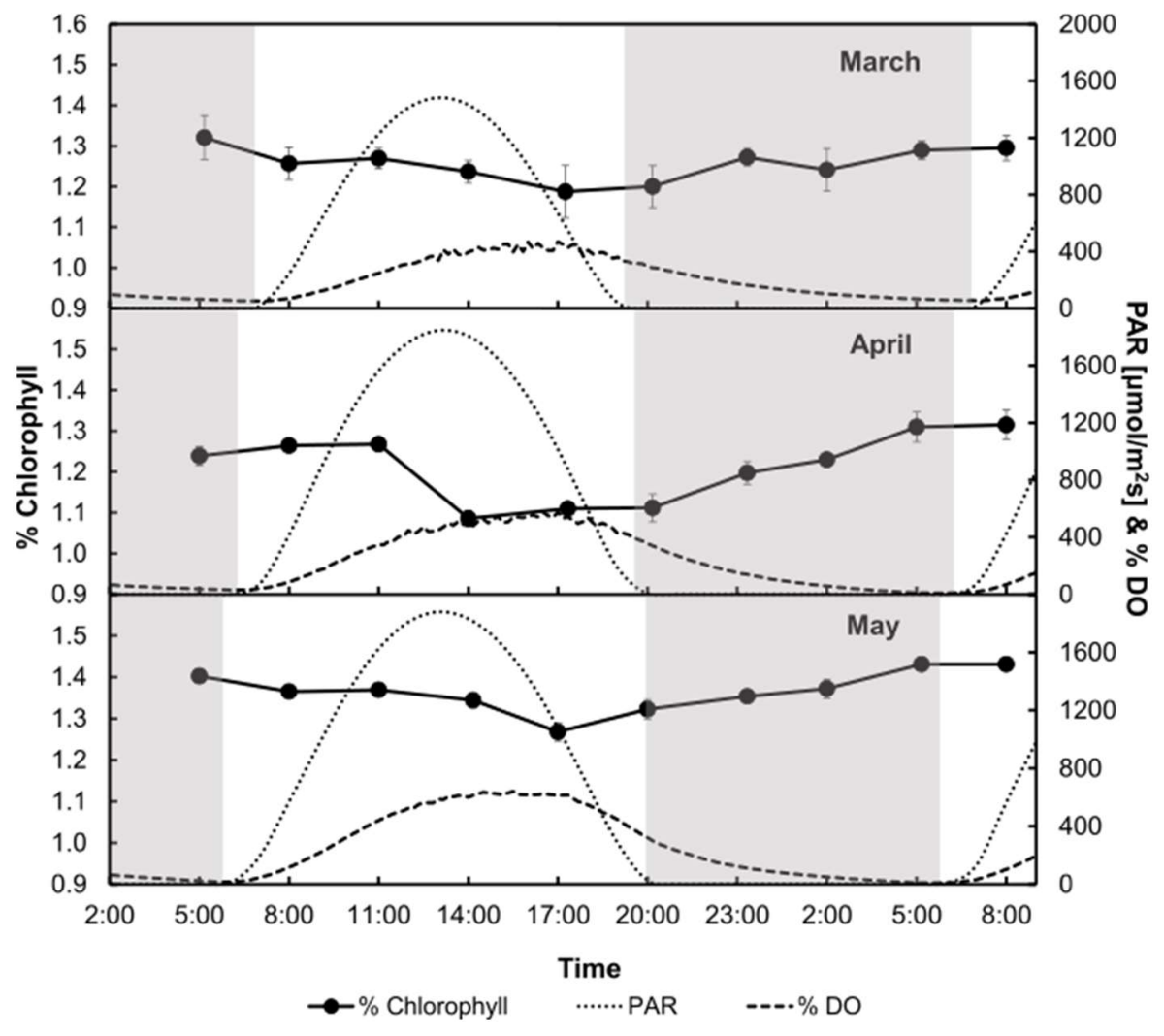

Fig. 5. \% chlorophyll a, PAR, and \% dissolved oxygen as a function of time throughout the March, April, and May experiments in a largescale raceway pond; mean \pm standard deviation

\# Single-column fitting image \# 


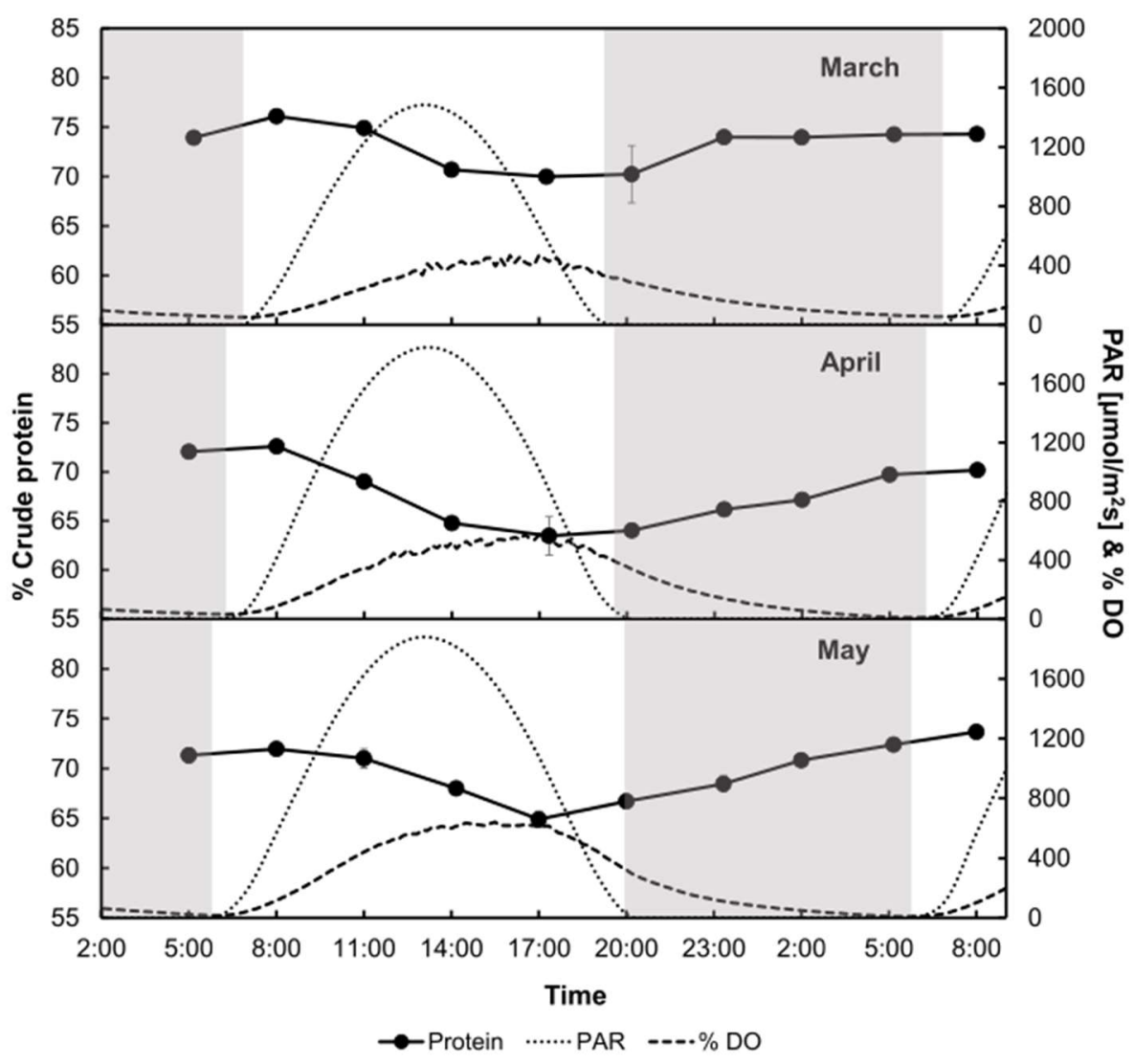

Fig. 6. \% crude protein, PAR, and \% dissolved oxygen as a function of time throughout the March, April, and May experiments in a largescale raceway pond; mean \pm standard deviation

\# Single-column fitting image \# 


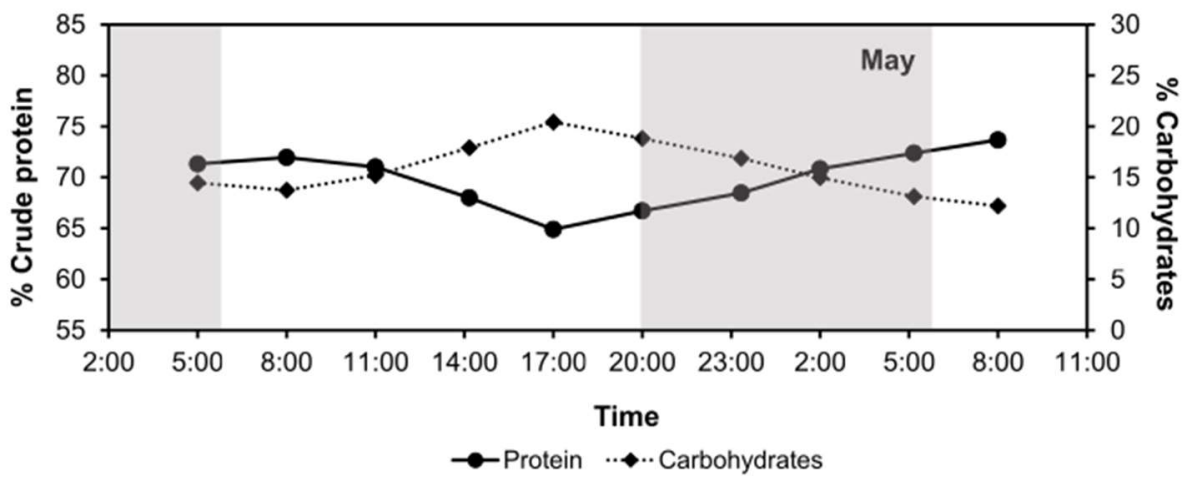

Fig. 7. \% crude protein and \% carbohydrates as a function of time throughout the May experiment in a large-scale raceway pond; mean \pm standard deviation

\# Single-column fitting image \# 


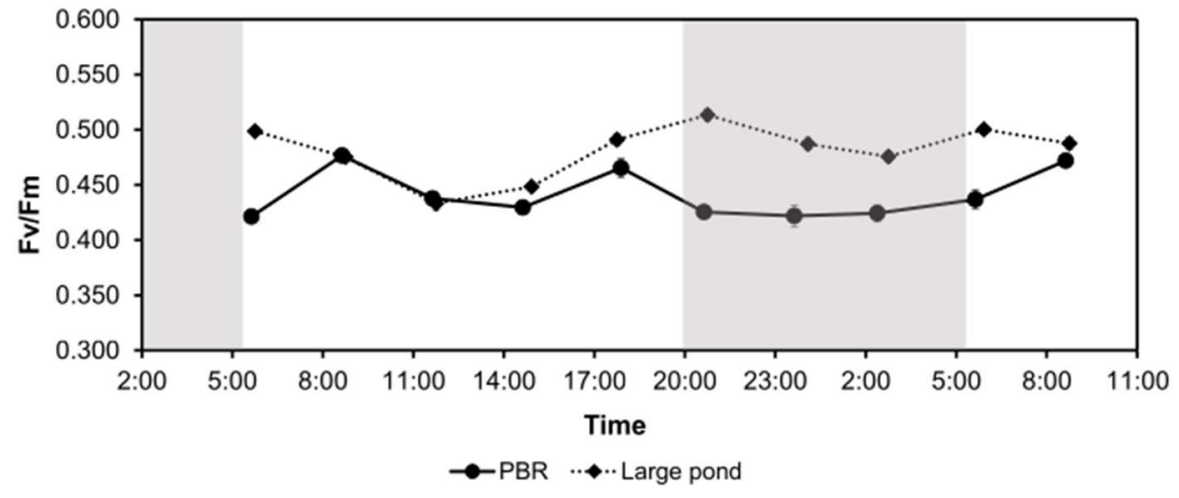

Fig. 8. Comparison of the Fv/Fm as a function of time in the large-scale raceway pond during the May experiment and in the photobioreactors during the May experiment laboratory simulation; mean \pm standard deviation

\# Single-column fitting image \# 


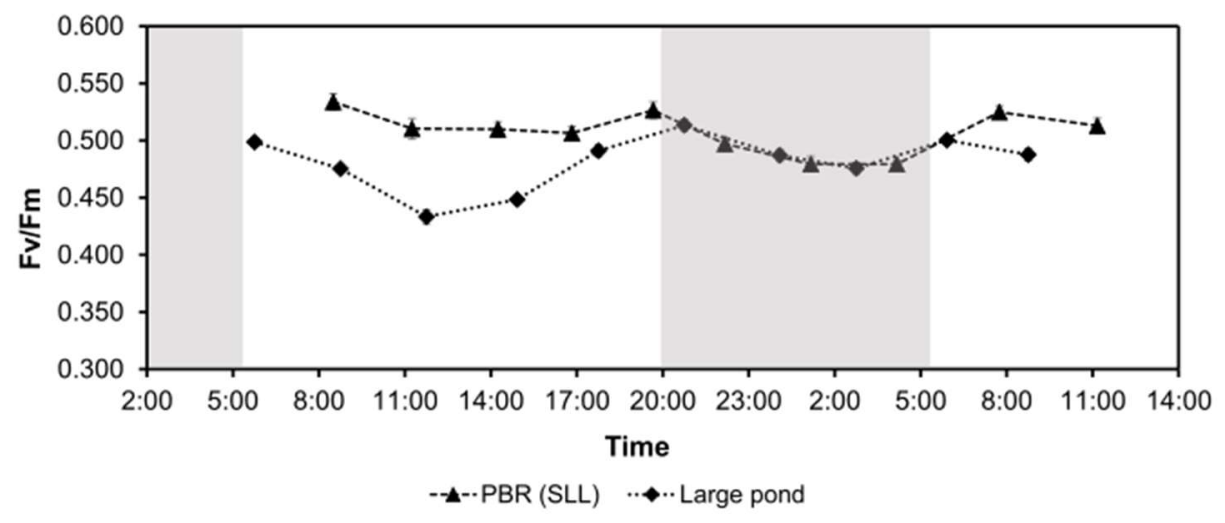

Fig. 9. Comparison of the Fv/Fm as a function of time in the large-scale raceway pond during the May experiment, and in a simulation in the photobioreactors with lower light intensities (SLL); mean \pm standard deviation

\# Single-column fitting image \# 


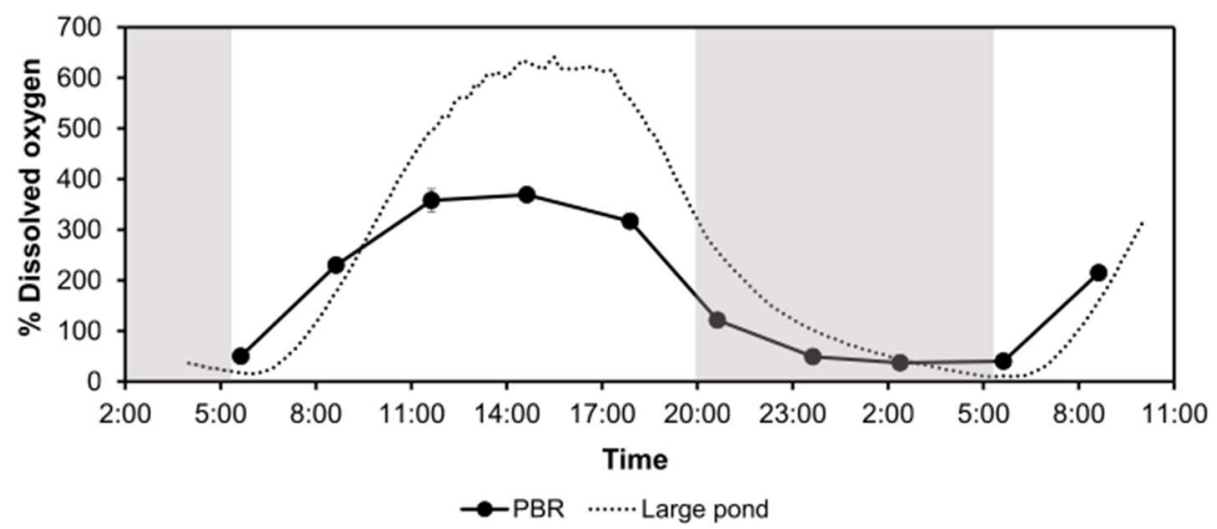

Fig. 10. Comparison of the \% dissolved oxygen as a function of time in the large-scale raceway pond during the May experiment and in the photobioreactors during the May experiment laboratory simulation; mean \pm standard deviation

\# Single-column fitting image \# 


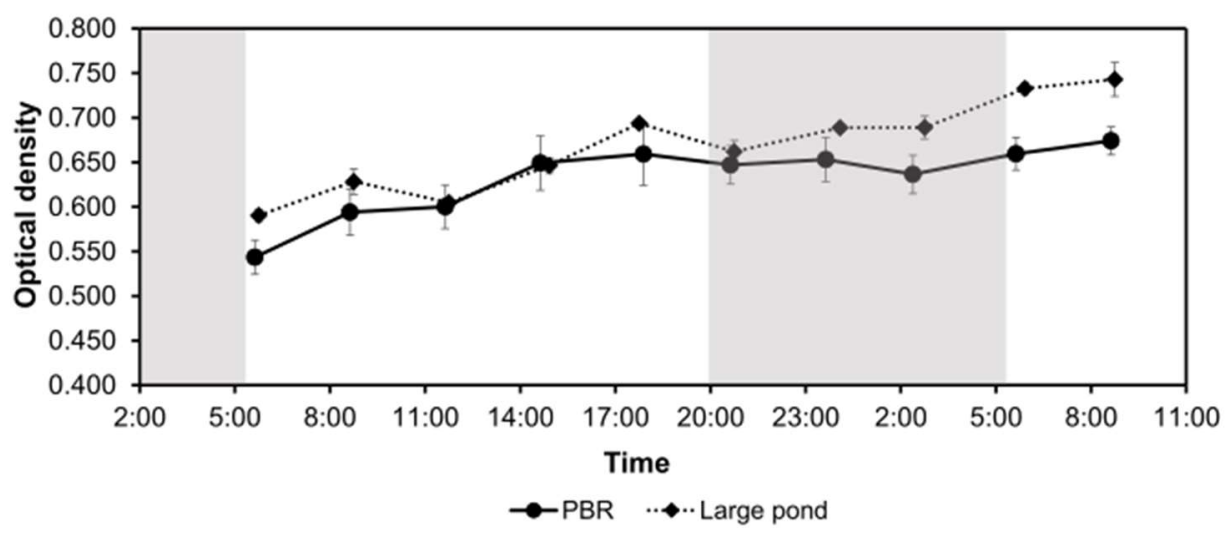

Fig. 11. Comparison of the optical density as a function of time in the large-scale raceway pond during the May experiment and in the photobioreactors during the May experiment laboratory simulation; mean \pm standard deviation

\# Single-column fitting image \# 


\begin{tabular}{llccc}
\hline & & March study & April study & May study \\
\hline \multirow{3}{*}{ \% Chlorophyll a } & Min. & $1.19 \pm 0.06$ & $1.09 \pm 0.02$ & $1.27 \pm 0.02$ \\
& Max. & $1.32 \pm 0.05$ & $1.27 \pm 0.01$ & $1.40 \pm 0.02$ \\
& \% Variation & 10 & 14 & 10 \\
\hline \multirow{3}{*}{ mg\% Total carotenoids } & Min. & $563 \pm 2$ & $492 \pm 8$ & $583 \pm 10$ \\
& Max. & $625 \pm 4$ & $566 \pm 5$ & $605 \pm 5$ \\
& \% Variation & 10 & $11.0 \pm 0.0$ & 4 \\
\% Total phycocyanin & Min. & $11.4 \pm 0.2$ & $14.0 \pm 0.3$ & $13.6 \pm 0.0$ \\
& Max. & $12.8 \pm 0.1$ & 21 & 19 \\
\hline
\end{tabular}

Table 1. Comparison of the morning maximum, afternoon minimum, and the percentage variation between the min. and max. values of the chlorophyll a, total carotenoids and total phycocyanin in the March, April, and May experiments in a large-scale raceway pond; value \pm standard deviation 


\begin{tabular}{llccc}
\hline & & March study & April study & May study \\
\hline \multirow{3}{*}{ \% Crude protein } & Min. & $70.0 \pm 0.5$ & $63.5 \pm 2.0$ & $64.9 \pm 0.8$ \\
& Max. & $76.1 \pm 0.3$ & $72.6 \pm 0.1$ & $72.0 \pm 0.4$ \\
& \% Variation & 8 & 13 & 10 \\
\hline \multirow{3}{*}{ \% Carbohydrates } & Min. & - & - & 13.7 \\
& Max. & - & - & 20.4 \\
& \% Variation & - & - & 33 \\
\hline
\end{tabular}

Table 2. Comparison of the morning maximum, afternoon minimum and the percentage variation between the min. and max. values of the \% crude protein and comparison of the morning minimum, afternoon maximum and the percentage variation between the min. and max. values of the \% carbohydrates in the March, April, and May experiments in a large-scale raceway pond; value \pm standard deviation 